\title{
Contraceptive Method Preferences, Use and Satisfaction among Women of Reproductive Age (15-49 Years) in Umuahia, Abia State, Nigeria
}

\author{
Ukegbu AU*, Onyeonoro UU, Nwokeukwu HI and Okafor GOC
}

Department of Community Medicine, Federal Medical Centre, Umuahia, Abia State, Nigeria

*Corresponding author: Ukegbu AU, Department of Community Medicine, Federal Medical Centre, Umuahia, Abia State, Nigeria, Tel: 8033906550; E-mail: andyukegbu@yahoo.com

Received date: June 20, 2018; Accepted date: June 28, 2018; Published date: July 5, 2018

Copyright: (C) 2018 Ukegbu AU et al. This is an open-access article distributed under the terms of the Creative Commons Attribution License, which permits unrestricted use, distribution, and reproduction in any medium, provided the original author and source are credited.

Citation: Ukegbu AU, Onyeonoro UU, Nwokeukwu HI, Okafor GOC (2018) Contraceptive Method Preferences, Use and Satisfaction among Women of Reproductive Age (15-49 Years) in Umuahia, Abia State, Nigeria. J Contracept Stud Vol.3 No.3:16

\section{Abstract}

Background: Low contraceptive practice is a major contributory factor to expansive population growth, high risk pregnancies, unsafe abortions, and sexually transmitted diseases. The study determined the pattern of use of contraceptive methods and associated factors among 232 women aged 15-49 years in Umuahia, Nigeria.

Methods: A community-based cross sectional study using multistage sampling technique to select 232 participants was conducted. Data were collected by interviewer administered questionnaire. The Chi square test and binary logistic regression were used to assess association between contraceptive use and related factors. The knowledge of the women on contraceptives was assessed using 26 tested and scored questions.

Results: The mean age of the women was $25.05 \pm 5.33$ years. Awareness of contraceptive was very high (96.6\%), but their in-depth knowledge was low as only $12.5 \%$ had good knowledge about contraceptives. The Media (Radio/TV) was the main source of information (37.6\%), followed by relatives/friends (31.4\%). Ever use of contraceptives was $39.2 \%$, while only $18.5 \%$ were currently using contraceptives. The most preferred and used contraceptive was condom (45.5\%) which was considered satisfactory by the women. Fear of side effects (41.1\%) was the main reason for non-use of any contraceptive method. Current use of contraceptives was associated with higher odds of being married $(O R=3.280$; $\mathrm{P}=0.025)$.

Conclusion: Despite high contraceptive awareness, knowledge and current contraceptive use among the study population were low. Therefore, there is need to design more effective reproductive health programmes, including education targeted at these group of women, but especially the unmarried.
Keywords: Contraceptive use; Satisfaction; Women; Reproductive age; Nigeria

\section{Introduction}

The world generally has witnessed rapid population growth within a short period of time. This growth is more accounted for by African and Asian continents. Nigeria is the most populous black country in the world, with an estimated population of about 140 million people and an annual growth rate of 3.2\% [1]. According to Khurfield [2], Nigeria is already facing a population explosion with a threat of food shortage for the growing population. The rapid population situation in Nigeria reduces her chances of realizing the goals of development, not only for the current generation but also for the future generations.

The fertility level in Nigeria is quite high. According to NDHS [3], the fertility rate is $5.7 \%$ which implies that an average Nigerian woman will bear approximately six children in her life time. In response to the increasing population, the national policy on population was formulated in 1998 and revised in 2004. A major goal of the policy is a reduction in fertility through increased adoption of contraception by couples [4].

Contraception is an important aspect of reproductive health care for women, their partners and their families. The potential of contraceptive practice in preventing unwanted pregnancy, achieving the number of children desired with appropriate spacing and timing, preventing high risk pregnancies, unsafe and unnecessary abortions, maternal and neonatal deaths, as well as reproductive tract infections and sexually transmitted infections, including HIV/AIDS have been reported [5,6].

Failure to plan a pregnancy can adversely affect the health of the mother, the child and the family as a whole. Rosmaus et al. reported that the risk of maternal morbidity and mortality is reduced considerably when the number of pregnancies women have in their life time is reduced [7]. 
There are wide ranges of contraceptive methods. These include the barrier methods, oral pills, IUCDS, injectables, natural methods and surgical methods. However, the effectiveness, safety, side effects, contraindications and availability of these methods vary, and may also influence their choice and use by individuals and satisfaction derived therefrom. Successful use and compliance with family planning methods are strongly associated with the woman's satisfaction and choice of the method [8].

Globally, many women who are sexually active would prefer to avoid being pregnant or delay their next pregnancy. Unfortunately, these women are not using any method of contraception, and where they do, use less effective methods. A report by the United Nations indicate that about 120-165 million women including 12-15 million unmarried women want to prevent or space their pregnancies, but are not using any contraceptive methods. These women are considered to have "unmet need" for family planning and are thus no doubt exposed to unwanted and unintended pregnancies and likely unsafe abortions [9].

Despite various programs initiated to promote family planning practice in Nigeria, reviews of successive contraceptive data by NDHS $[3,10,11]$ show that there is no significant change in the level of contraceptive use. The 1999 report showed that only $6 \%$ used any contraceptive method, while in 2003 the usage rate for any method by the women was $13 \%$. The 2008 report revealed that only $29 \%$ of all reproductive age women reported ever using a method of contraception, and contraceptive prevalence rate (CPR) was only $14.6 \%$ for any method. The reasons attributed to this low prevalence were largely due to culture that is highly supportive of large family size, misconceptions about family planning methods, and male child preference.

Low use of contraceptives in Nigeria, despite their availability lead to series of problems such as unintended and unwanted pregnancies with its attendant consequences, including physical and psychosocial health problems and unsafe abortions, undesirable child spacing, maternal mortality and morbidity. Unintended and unwanted pregnancies are major problems in Nigeria. Ezechi et al. showed that $80.4 \%$ pregnancies were terminated by patients in South West Nigeria because they were unwanted [12]. Most abortions are performed under unsafe conditions and by nonphysicians, with severe health consequences for the women.

Since abortion is illegal in Nigeria, an increase in the number of unwanted pregnancies because of unmet need for family planning is likely to result in an increase in the number of these unsafe abortions. This will in turn likely raise the proportion of women with complications of abortion, and the net effect will be an increased burden on the countries already overwhelmed health care system.

Reducing the unmet need for contraception in Nigeria will require more understanding of the factors that influence contraceptive choices and use, so as to achieve population and development goals.
The study was conducted to determine the preferences and use of contraceptive methods and associated factors among women of reproductive age (15-49 years) in Umuahia community, Abia state.

\section{Methods}

\section{Study design}

This was a community-based cross sectional descriptive study.

\section{Study setting}

The study area of this research work is Umuahia, Abia state, South Eastern Nigeria. Umuahia is the capital of Abia state, with two Local Government Areas, namely Umuahia North and Umuahia South. The area is made up of five traditional clans (Ibeku, Ohuhu, Olokoro, Ubakala and Umuokpara).

According to the 2009 national census [13], the population of Umuahia is 389,120 . The inhabitants are mostly civil servants, traders, farmers, artisans, and students. The Roman Catholic faith is widely practiced among the people, though a large number also belong to other Christian faith. Very few are Muslims and Traditionalists. There are many primary health centers and private hospitals, in addition to one secondary and one tertiary health facility in the area. Majority of these facilities offer family planning services.

\section{Study size and sampling}

The population of this study was all women within the reproductive age group of 15-49 years, married or unmarried and resident in Umuahia. Those who had infertility problem or refused to participate in the study were excluded.

The sample size calculation formula for population greater than 10,000 was used [14].

$$
n=\frac{\mathrm{Z}^{2} \mathrm{P}(1-\mathrm{P})}{\mathrm{d}^{2}} \text { Where } \mathrm{n} \text { is the desired sample size }
$$

$\mathrm{Z}=$ standard normal deviate set at 1.96 which corresponds to the $95 \%$ confidence level

$\mathrm{P}=$ proportion of women using any method of contraception (15\%) [3]

$$
d=\text { level of precision (0.05). }
$$

Substituting,

$\frac{1.96^{2} \times 0.15 \times 0.85}{0.0025}=196$. Assuming non response rate of $10 \%$, the sample size was increased to 216 . In this study however, 232 subjects were used.

A multistage sampling technique was employed in sample selection. Each traditional clan formed a cluster, making a total of five clusters. Two clusters (Ibeku and Ubakala) were selected by simple random sampling (simple balloting). A modified World Health Organization (WHO) cluster sampling technique was used to select the subjects. The central point of each 
selected cluster was identified and from that point, an empty bottle was spun flat on the ground. Wherever the neck of the bottle pointed, the compound or house nearest to it in that direction became the starting point for selection of every eligible consenting subject(s). This selection was continued sequentially until the required number of subjects (116 from each cluster) was obtained.

\section{Ethical consideration}

Ethical approval for this study was obtained from the Research and Ethics Committee of the Federal Medical Centre, Umuahia. Subsequently, informed written consent was obtained from the participants at the commencement of the study. Additionally, confidentiality was expressed at the introductory part of the questionnaire.

\section{Data collection}

The data was collected using interviewer administered questionnaire. The questionnaire obtained information on the socio-demographic characteristic of the respondents, awareness, knowledge, preference, use and satisfaction of contraceptive methods. The administration of the questionnaires was done by the researcher and five trained research assistants (RAs) in the houses of respondents.

\section{Validity and reliability of instrument}

Prior to data collection, the questionnaire was validated by four lecturers in the Department of Community Medicine, NnamdiAzikiwe University Teaching Hospital, Nnewi. It was thereafter pretested on 50 women of reproductive age in two different communities in Owerri North and West LGAs to assess its appropriateness, content clarity and comprehensiveness. Thereafter, corrections were made.

\section{Data analysis}

The SPSS version 17.0 (SPSS Inc. Chicago IL, USA) [15] statistical package was used for data entry and analysis. Data was summarized using frequency tables, graphs, means and standard deviations. The Chi square test was performed to assess association between explanatory variables and contraceptive use. Variables significant at 0.05 level were included in multivariate analysis and assessed by binary logistic regression. Odd ratios (OR) and their 95\% confidence intervals (Cls) were reported. The knowledge of the women on contraceptives was assessed using 26 tested and scored questions. Each correct answer was scored ' 1 ' point and wrong answer was scored ' 0 ' point. The scores were rated as follows: 0-12=poor,13-26=good.

\section{Results}

Table 1 Socio-demographic characteristics of respondents $(n=232)$.

\begin{tabular}{|c|c|c|}
\hline Variable & $\begin{array}{l}\text { Frequen } \\
\text { cy }\end{array}$ & $\begin{array}{l}\text { Percentag } \\
\text { e (\%) }\end{array}$ \\
\hline \multicolumn{3}{|l|}{ Age (years) } \\
\hline$\leq 24$ & 132 & 56.9 \\
\hline 25 and above & 100 & 43.1 \\
\hline \multicolumn{3}{|c|}{ Mean age $=25.05 \pm 5.33$ years; Median age $=23$ years } \\
\hline \multicolumn{3}{|l|}{ Marital status } \\
\hline Never married/single & 154 & 66.4 \\
\hline Married & 78 & 33.6 \\
\hline \multicolumn{3}{|l|}{ Parity } \\
\hline $0-3$ & 217 & 93.5 \\
\hline 4 above & 15 & 6.5 \\
\hline \multicolumn{3}{|l|}{ Family type } \\
\hline Monogamous & 206 & 88.8 \\
\hline Polygamous & 26 & 11.2 \\
\hline \multicolumn{3}{|c|}{ Highest level of education } \\
\hline Secondary & 29 & 12.5 \\
\hline Tertiary & 203 & 87.5 \\
\hline \multicolumn{3}{|l|}{ Main occupation } \\
\hline Unemployed & 182 & 78.5 \\
\hline Employed & 50 & 21.5 \\
\hline \multicolumn{3}{|l|}{ Place of residence } \\
\hline Rural & 30 & 12.9 \\
\hline Urban & 202 & 87.1 \\
\hline \multicolumn{3}{|c|}{ Religious denomination } \\
\hline Roman Catholic & 86 & 37.1 \\
\hline Other Denominations & 146 & 62.9 \\
\hline
\end{tabular}

Table 1 shows the socio-demographic characteristics of the respondents. Their mean age was $25.05 \pm 5.33$ years. Majority 132 (56.9\%) were within the age range of $15-24$ years. About 154 (66.4\%) were single or never married, while 78 (33.6\%) were married. They were mostly unemployed 182 (78.5\%), and all had completed at least secondary education. Majority, 217(93.5\%) had 0-3 children, belonged to a monogamous family 206 (88.8\%), lived in urban areas 202 (87.1\%), and of the non Roman Catholic faith 146 (62.9\%).

Table 2 Awareness and knowledge of modern contraceptive methods among respondents.

\begin{tabular}{|l|l|l|}
\hline Variable & Frequency & $\begin{array}{l}\text { Percentage } \\
\text { (\%) }\end{array}$ \\
\hline Heard of contraceptives $(\mathbf{n}=\mathbf{2 3 2})$ & \multicolumn{2}{|l|}{} \\
\hline Yes & 224 & 96.6 \\
\hline No & 8 & 3.4 \\
\hline
\end{tabular}




\begin{tabular}{|c|c|c|}
\hline \multicolumn{3}{|l|}{ Types heard of $(n=224)$} \\
\hline Safe period/rhythm & 75 & 33.4 \\
\hline Withdrawal & 86 & 38.4 \\
\hline Breastfeeding & 35 & 15.6 \\
\hline Billings or ovulation method & 47 & 21 \\
\hline Condom & 130 & 58 \\
\hline Oral contraceptive pills & 109 & 48.7 \\
\hline Injectable & 49 & 21.9 \\
\hline IUCD & 52 & 23.2 \\
\hline Implant & 28 & 12.5 \\
\hline Diaphragm & 31 & 13.8 \\
\hline Vaginal cream or foam & 30 & 13.4 \\
\hline Vasectomy & 20 & 8.9 \\
\hline Tubal ligation & 25 & 11.6 \\
\hline Emergency pills & 39 & 17.4 \\
\hline \multicolumn{3}{|l|}{ Knowledge score $(n=224)$} \\
\hline Poor & 196 & 87.5 \\
\hline Good & 28 & 12.5 \\
\hline
\end{tabular}

Table 3 Current and ever use of contraceptive method.

\begin{tabular}{|l|l|l|}
\hline Contraceptive method & Current use (n=44) & Ever use (n=91) \\
\hline Withdrawal & $4(9.1 \%)$ & $7(7.7 \%)$ \\
\hline Safe period/rhythm & $7(15.9 \%)$ & $7(7.7 \%)$ \\
\hline Condom & $20(45.5 \%)$ & $44(48.4 \%)$ \\
\hline Oral contraceptive pill & $6(13.6 \%)$ & $24(26.3 \%)$ \\
\hline Injectable & $3(6.8 \%)$ & $3(3.3 \%)$ \\
\hline IUCD & $1(2.3 \%)$ & $3(3.3 \%)$ \\
\hline Tubal ligation & $1(2.3 \%)$ & $1(1.1 \%)$ \\
\hline Breast feeding & $2(4.5 \%)$ & $2(2.2 \%)$ \\
\hline
\end{tabular}

Table 3 shows current and ever use of contraceptives among respondents. Only 91 (39.2\%) of the respondents had ever used contraceptive method. Condom (male) was the commonest method used 44 (48.4\%). As at the period of the study, the proportion currently using contraceptives stood at $44(18.5 \%)$. The most used method was male condom 20 $(45.5 \%)$, while the least used were IUCD and tubal ligation 1 (2.3\%).

Table 4 Reasons for choosing type of contraceptive method by both ever use and current users.

Awareness and knowledge of modern contraceptive methods is as depicted in Table 2. A high proportion of the respondents 224 (96.6\%) were aware of contraceptives. The common types they were aware of include condom 130 $(58.0 \%)$, oral contraceptive pill $109(48.7 \%)$, withdrawal 86 (38.4\%), and safe period/rhythm 75 (33.4\%). The least contraceptives aware of where tubal ligation 25 (11.6\%) and vasectomy 20 (8.9\%). With regards to their knowledge of contraceptives, only few 28 (12.5\%) had good knowledge.

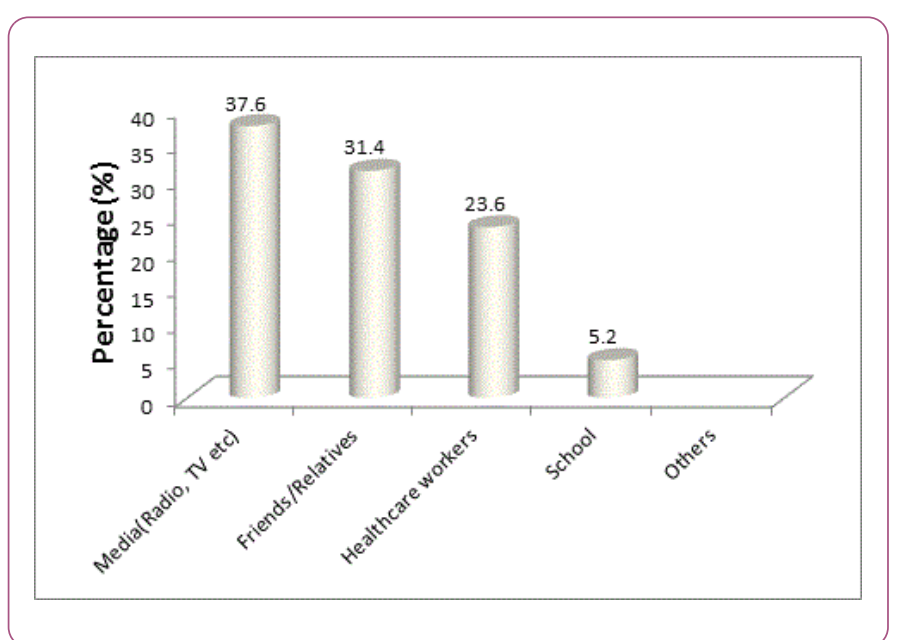

As shown in Figure 1, the main source of information on contraceptive methods was the media (37.6\%), followed by friends/relatives (31.4\%), and health care workers (23.6\%).

\begin{tabular}{|l|l|l|}
\hline Reason & $\begin{array}{l}\text { Frequenc } \\
\text { y }\end{array}$ & Percentage (\%) \\
\hline Effective for preventing pregnancy & 69 & 75.8 \\
\hline Inexpensive & 23 & 25.3 \\
\hline Easy to use & 29 & 31.9 \\
\hline Acceptable by religion/culture & 3 & 3.3 \\
\hline Recommended by Health worker & 24 & 26.4 \\
\hline Protects against infection & 21 & 23.1 \\
\hline Causes fewer side effects & 21 & 23.1 \\
\hline Recommended by relatives/friends & 23 & 55.3 \\
\hline
\end{tabular}

The reason for choosing type of contraceptive method by both ever use and current users is as shown in Table 4. Majority $(75.8 \%)$ chose contraceptive method because it is effective for preventing pregnancy, followed by the fact that it is recommended by relatives/friends $(55.3 \%)$. Other reasons were, easy to use $(31.9 \%)$, recommended by health workers $(26.4 \%)$, protects against infection and causes fewer side effects (23.1\% each).

Table 5 Level of satisfaction with contraceptive method among current users $(n=44)$.

\begin{tabular}{|l|l|l|}
\hline Level of satisfaction & Frequency & Percentage (\%) \\
\hline Satisfied & 38 & 86.3 \\
\hline Indifferent & 1 & 2.3 \\
\hline Dissatisfied & 5 & 11.4 \\
\hline
\end{tabular}


Majority of current users of contraceptives 38 (86.3\%) were satisfied with contraceptive method used. Only 5 (11.4\%) expressed dissatisfaction with contraceptive method (Table 5).

Table 6 Reasons for non-use of any contraceptives ( $n=141)$.

\begin{tabular}{|l|l|l|}
\hline Reason & $\begin{array}{l}\text { Frequenc } \\
\text { y }\end{array}$ & Percentage (\%) \\
\hline Against my religion/culture & 9 & 6.4 \\
\hline Not acceptable by husband/partner & 16 & 11.3 \\
\hline Desire to be pregnant & 11 & 7.8 \\
\hline Not engaged in sexual activity & 20 & 14.2 \\
\hline Can cause health problems & 27 & 19.2 \\
\hline Fear of side effects & 58 & 41.1 \\
\hline
\end{tabular}

Fear of side effects 58 (41.1\%) was the main reason for nonuse of any contraceptive method. Similarly, 27 (19.2\%) believed it can cause health problems, while 20 (14.2\%) deemed it unnecessary since they were not engaged in sexual activity. It was not acceptable by husband/partner among 16 (11.3\%) of the respondents. Desire to be pregnant $11(7.8 \%)$ and against religion/culture $9(6.4 \%)$ were other reasons for non-use of contraceptives (Table 6).

Table 7 Respondents' characteristics associated with current use of contraceptive methods.

\begin{tabular}{|c|c|c|c|c|c|}
\hline \multirow[b]{2}{*}{ Characteristics } & \multicolumn{2}{|c|}{$\begin{array}{l}\text { Contraceptive current } \\
\text { use }\end{array}$} & \multirow[t]{2}{*}{$\begin{array}{l}\text { Total } \\
{[\mathrm{N}]}\end{array}$} & \multirow[t]{2}{*}{$x^{2}$} & \multirow[t]{2}{*}{$\begin{array}{l}p- \\
\text { valu } \\
\text { e }\end{array}$} \\
\hline & $\begin{array}{l}\text { Yes } \\
(\%)]\end{array} \quad[N$ & $\begin{array}{l}\left.\begin{array}{l}\text { No } \\
(\%)]\end{array}\right] \text { [N }\end{array}$ & & & \\
\hline \multicolumn{6}{|l|}{ Age group } \\
\hline$\leq 24$ & $15(11.4)$ & $\begin{array}{l}117 \\
(88.6)\end{array}$ & 132 & \multirow[t]{2}{*}{$\begin{array}{l}11 . \\
52\end{array}$} & \multirow[t]{2}{*}{$\begin{array}{l}0.001 \\
*\end{array}$} \\
\hline 25 and above & $29(29.0)$ & 71 (71.0) & 100 & & \\
\hline \multicolumn{6}{|l|}{ Main occupation } \\
\hline Unemployed & $27(14.8)$ & $\begin{array}{l}155 \\
(85.2)\end{array}$ & 182 & \multirow[t]{2}{*}{$\begin{array}{l}9.3 \\
7\end{array}$} & \multirow[t]{2}{*}{$\begin{array}{l}0.002 \\
*\end{array}$} \\
\hline Employed & $17(34.0)$ & $33(66.0)$ & 50 & & \\
\hline \multicolumn{6}{|l|}{ Marital status } \\
\hline $\begin{array}{l}\text { Never married/ } \\
\text { single }\end{array}$ & $16(10.4)$ & $\begin{array}{l}138 \\
(89.6)\end{array}$ & 154 & \multirow{2}{*}{$\begin{array}{l}21 . \\
92\end{array}$} & \multirow{2}{*}{$\begin{array}{l}0.000 \\
*\end{array}$} \\
\hline Married & $28(35.9)$ & $50(64.1)$ & 78 & & \\
\hline \multicolumn{6}{|c|}{ Highest educational level } \\
\hline Secondary & $8(27.6)$ & $21(72.4)$ & 29 & & \\
\hline Tertiary & $36(17.7)$ & $\begin{array}{l}167 \\
(82.3)\end{array}$ & 203 & 1.6 & 0.206 \\
\hline Parity & & & & & \\
\hline
\end{tabular}

\begin{tabular}{|c|c|c|c|c|c|}
\hline $0-3$ & 35 (16.1) & $\begin{array}{l}182 \\
(83.9)\end{array}$ & 217 & \multirow[t]{2}{*}{$\begin{array}{l}17 . \\
57\end{array}$} & \multirow[t]{2}{*}{$\begin{array}{l}0.000 \\
*\end{array}$} \\
\hline$\geq 4$ & $9(60.0)$ & $6(40.0)$ & 15 & & \\
\hline \multicolumn{6}{|c|}{ Knowledge } \\
\hline Poor & $32(16.3)$ & $\begin{array}{l}164 \\
(83.7)\end{array}$ & 196 & \multirow[t]{2}{*}{$\begin{array}{l}5.7 \\
2\end{array}$} & \multirow[t]{2}{*}{$\begin{array}{l}0.017 \\
*\end{array}$} \\
\hline Good & $12(33.3)$ & $24(66.7)$ & 36 & & \\
\hline
\end{tabular}

Table 7 shows respondents characteristics associated with current use of contraceptive methods. Age, occupation, marital status and parity were significantly associated with current use of contraceptives $(p<0.05)$. Those who were older, married, employed and had more children were more likely to use contraceptives. Also having higher knowledge increased the probability of using modern contraceptive methods.

Table 8 Multiple logistic regression for current contraceptive use.

\begin{tabular}{|l|l|l|l|}
\hline Characteristics & OR & $\mathbf{9 5 \%} \mathbf{C l}$ & P value \\
\hline Age group (years) & 1.297 & $0.500-3.361$ & 0.593 \\
\hline Main occupation & 0.865 & $0.331-2.258$ & 0.767 \\
\hline Marital status & 3.280 & $1.161-9.269$ & $0.025^{*}$ \\
\hline Parity & 3.294 & $0.987-10.986$ & 0.052 \\
\hline Knowledge & 2.243 & $0.942-5.343$ & 0.068 \\
\hline $\begin{array}{l}\text { OR=Adjusted odds ratio, Cl=confidence interval } \\
\text { "Significant at } p<0.05\end{array}$ \\
\hline
\end{tabular}

From the regression analysis, a positive and significant association was observed between contraceptive use and marital status (OR=3.280; 95\% Cl [1.161-9.269]). There was also a positive but non significant association between older women (OR=1.297; 95\% Cl [0.500-3.361]), having more children (OR=3.294; $95 \% \mathrm{Cl}$ [0.987-10.986]), having good knowledge about contraceptives (OR=2.243; $95 \% \mathrm{Cl}$ [0.942-5.343]), and contraceptive use. A negative association was found between main occupation $(\mathrm{OR}=0.865 ; 95 \% \mathrm{Cl}$ [0.331-2.258]), and contraceptive use (Table 8).

\section{Discussion}

The study examined the use of contraceptive methods and the factors that influence their use among women of reproductive age group (15-49 years) in Umuahia. The mean age of the study population was $25.05 \pm 5$.33years and a median age of 23 years. Thus, half of the study population will still be in the reproductive age group (15-49years) in the next 26 years and would require one form of contraceptive method or the other to control their fertility.

The study shows that majority of the women (96.6\%) were aware of modern contraceptive methods. This is consistent with findings reported by other researchers in Nigeria and other developing countries $[16,17]$. However, there is a gap 
between their awareness and knowledge of modern contraceptive methods, as only (12.5\%) had good knowledge about modern contraceptives. The low knowledge is showcased by the low contraceptive usage (both ever and current) and the fear of side effects given as the main reason for non-use of any contraceptives. This probably means that the information they received was inadequate. One of the greatest obstacles to family planning in developing countries is inadequate knowledge. An individual can only accept to take contraceptives if she has an in-depth knowledge of what they are, the likely side effects and above all the benefits accruing to the individual for using it [18]. The Radio/TV (37.6\%) and friends/relations (31.4\%) were the main sources the respondents obtained their information on modern contraceptive methods. According to Oye-Adeniran et al. [19], information provided by such groups or channels are often incomplete or inaccurate. More reliable information about contraceptives is usually provided by health workers at family planning or antenatal clinics [20]. It is noteworthy that a greater proportion of the population in this study was made up of very young and unmarried women who may not have any need of visiting these clinics and thus may not have the opportunity of receiving contraceptive information from health workers.

Otoide et al. [21] have reported earlier that family planning clinics are not young women-friendly and young women may still regard family planning clinic as a facility essentially established for married people. Hence it becomes imperative for programme managers to design other appropriate and effective channels that are youth-friendly for health workers to pass information on modern contraceptives to this group of people.

This study also found out that $39.2 \%$ of the respondents had ever used contraceptives. This substantially dropped as current use (prevalence rate) stood at $18.5 \%$. This rate is far lower than that reported among female traders in Jos [22], but comparable to $15 \%$ reported by the Nigerian Demographic and Health Survey [3], and other studies carried out in Africa which have shown low contraceptive prevalence rates [23,24]. The low contraceptive prevalence in this study area means increased risk of unintended and unwanted pregnancies which may result to illegal and unsafe abortions and associated consequences, including psychosocial problems, maternal morbidity and death. This finding and likely implications call for immediate action by policy makers and health planners to target this part of the society in family planning programmes in order to achieve increased uptake of modern contraceptive methods.

The condom was the most preferred contraceptive method and commonly used by majority of the study population because they believe it is effective, easy to use, inexpensive and recommended by either relatives, friends or health workers. Eko et al. [25] reported similar findings in a study carried out among women of reproductive age in Calabar. They observed that the reasons for their choice of condom were reliability, affordability and availability. Condoms are accessible, affordable, and easy to apply or use and its side effects are minimal [16]. Condoms are readily available over the counter. Additionally, in recent times, condom has enjoyed global advertisement and social marketing, supported by governments and non-governmental organizations as a cost effective and reliable tool in the prevention of sexually transmitted infections, including HIV/AIDS. This probably accounted for this observation. The adoption of this approach in the promotion of other contraceptives may increase their use in Nigeria [20]. This suggestion is instructive because women who prefer condom may not be consistent with its use, as it would also require partners' endorsement.

The long acting and permanent contraceptives like the IUCD and tubal ligation were the least used. The likely reason for this is that majority of the respondents were still young, single or unmarried. This observation is corroborated by Mekonnen et al, in a community-based cross sectional study among women of reproductive age in Ethiopia which showed that majority of the women were using modern contraceptive methods other than long acting and permanent ones because they were single [26]. Added to this is the likelihood that the studied population do not have enough information regarding these long acting methods.

It is worrisome to note that $121(85.8 \%)$ of the 141 respondents not using any form of contraceptives are sexually active. Several reasons were given by the respondents for nonuse of contraceptives. Fear of side effects and perceived health problems were the main reasons for non-use of contraceptive methods. Fear of contraceptive side effects were reported as major reasons for non-use in south west Nigeria [20] and in Democratic Republic of Congo [27]. The fear of side effects and perceived health problems may be as a result of inadequate information received by the respondents, as reflected by their low knowledge of modern contraceptives in this study.

Current use of contraceptives was significantly influenced by marital status. Married women were more likely to be current users compared with their unmarried counterparts. Envulandu et al. [22] observed that married women are more likely to use contraceptives in our culture where family planning is considered to be sorely meant for married women, who are also expected to be sexually active [16].

In addition, women with four or more children were more likely to be current users of contraceptives. This relationship may be due to the desire by the women to limit and/or space childbirth, as well as for economic reasons. This is supported by a study in Umuahia [28] which showed that the desired family size among majority of respondents was four and this was mainly due to financial considerations

Apart from the predictive variables identified in the regression model, other factors that were common with use of contraceptives were age of the women and knowledge of contraceptive methods. Older women were more likely to use contraceptive methods than younger ones. This may have negative implications on the future trends of family planning utilization. Non use of contraceptives also puts young women 
at greater risk of unplanned and unwanted pregnancy with attendant illegal abortions and complications.

\section{Conclusion}

Despite high contraceptive awareness, knowledge and current contraceptive use among the study population were low, with fear of side effects as a major barrier. However, users expressed satisfaction with preferred contraceptive methods because of their effectiveness in preventing pregnancy. Thus gaps in knowledge of modern contraceptive methods among the women need to be addressed through intensive reproductive health education involving trained health care providers (in a marital and age specific friendly environment) to correct misconceptions and myths associated with contraceptives.

\section{References}

1. National Population Commission. Nigeria Demographic and Health Survey (2006) Calverton, MD: NPC and ICF Macro.

2. Khurfield M. Thousands feared born in Nigeria's population explosion. The Onion.

3. Nigeria Demographic and Health Survey (2008) National Population Commission and ORC/ Macro. Calverton, Maryland, USA.

4. Federal Government of Nigeria (2004) National Policy on population for sustainable development. Policy Document.

5. Moronkola OA, Ojediran MM, Amosun A (2006) Reproductive Health Knowledge, beliefs and determinants of contraceptives use among women attending family planning clinics in Ibadan, Nigeria. Afr Health Sci 6: 155-159.

6. Leke RJI. Family planning in Africa south of the Sahara. Geneva foundation for medical education and research.

7. Rosmaus C, Campbell O (1998) Short birth intervals don't kill women: evidence from Matlab, Bangladesh. Stud Fam Plann 29: 282-290.

8. Aisen AO (2007) IUCD: acceptability and effectiveness in a tertiary institution. Afr J Med Med Sci 36: 193-200.

9. United Nations. World contraceptive use (2011).

10. Nigeria Demographic and Health Survey (1999) National Population Commission and ORC/Macro. Calverton, Maryland, USA.

11. Nigeria Demographic and Health Survey (2003) National Population Commission and ORC/Macro. Calverton, Maryland, USA.

12. Ezechi OC, Fasunbaa OB, Dare FO (1999) Abortion related deaths in South Western Nigeria. Nig J Med 8: 112-114.

13. National Population Commission. Nigeria Demographic and Health Survey (2009). Calverton, MD: NPC and ICF Macro.
14. Araoye MO (2003) Sample Size determination. In: Research methodology with statistic for health and social sciences. Ilorin: Nathadox Publishers.

15. SPSS Inc. Chicago IL, USA.

16. Asekun-Olarinmoye EO, Adebimkpe WO, Bamidele JO, Odu OO, Asekun-Olarinmoye IO, et al. (2013) Barriers to use of modern contraceptives among women in an inner city of area ofOsogbo metropolis, Osun state Nigeria. Int J Women's Health 5: 647-655.

17. Arbab AA, Bener A, Abdulmalik M (2011) Prevalence, awareness and determinants of contraceptive use in Qatari women. East Mediterr Health J 17: 11-18.

18. Addah AO, Abasi IJ, Ikobho EH, Ibrahim Al (2014) To determine the knowledge and attitudes on modern contraceptive use amongst antenatal attendees at the Niger Delta University Teaching Hospital, Okolobiri, South-South Nigeria. IOSR J Dent Med Sci 13: 1-7.

19. Oye-Adeniran BA, Adewole IF, Odeyemi KA, Ekanem EE, Umoh AV (2005) Contraceptive prevalence among young women in Nigeria. J Obstet Gynaecol 25: 182-185.

20. Abiodun OM, Balogun OR (2009) Sexual activity and contraceptive use among young female students of tertiary educational institutions in Ilorin, Nigeria. Contraception 79: 146-149.

21. Otoide VO, Oronsaye F, Okonofua FE (2001) Why Nigerian adolescents seek abortion rather than contraception: Evidence from focus-group discussions. Int Perspect SexReprod Health 27: 77-81.

22. Envulandu EA, Agbo HA, Mohammed A, Zoakah Ai (2012) Utilization of modern contraceptives among female traders in Jos South LGA of Plateau State, Nigeria. Int J Medicine Biomed Res 1: 224-231.

23. Hagan JE, Buxton C (2012) Contraceptive knowledge, perceptions and use among adolescents in selected senior high schools in the central region of Ghana. J Sociol Res 3: 170-180.

24. Lwelamira J, Mnyamagola G, Msaki MM (2012) Knowledge, attitude and practice towards modern contraceptives among married women of reproductive age in Mpwapara district central Tanzania. Curr Res J Soc Sci 4: 235-245.

25. Eko JE, Osonwa KO, Osuchukwu NC, Offiong DA (2013) Prevalence of contraceptive use among women of reproductive age in Calabar Metropolis, Southern Nigeria. Int J Humanities Soc Sci Inventions 2: 27-34.

26. Mekonnen G, Enquselassie F, Tesfaye G, Semahegn A (2014) Prevalence and factors affecting use of long acting and permanent contraceptive methods in Junka town, Southern Ethiopia: a cross sectional study. Pan Afr Med J.

27. Izale K, Govender I, Fina JPL, Tumbo J (2014) Factors that influence contraceptive use amongst women in Vanga health district, Democratic Republic of Congo. Afr J Prim Health Care Fam Med 6: 599.

28. Nduka EC, Nduka I, Nwachukwu KC (2014) Desired family size in Umuahia, South-East Nigeria. Pioneer Med J 4: 1-9. 